\title{
A HISTÓRIA DE ESMERALDA E SEUS CADERNOS DE RECEITAS
}

\author{
Elra Fagundes da Silva \\ Alboni Marisa Dudeque Pianouski Vieira
}

Resumo

O artigo, na perspectiva da História Cultural, analisa os cadernos de receitas como fontes documentais e como peças importantes do acervo familiar e cultural por sua representatividade na memória e na transmissão de saberes entre gerações. Trata da história de vida de N.L.M, neste artigo chamada de Esmeralda, nascida e criada no interior do estado do Paraná, Brasil. A pesquisa é bibliográfica, documental e de campo. Os cadernos de receitas são testemunhos de uma época e tratam de uma forma de vida centrada na família, à medida que pretendem sistematizar a vivência alimentar desse grupo. Sua análise revela não apenas aspectos relativos à autora, como emoções, lembranças e tradições familiares, mas também vestígios sobre o que privilegiava a educação feminina da época.

Palavras-chave: educação; história; cadernos de receitas

\section{THE HISTORY OF ESMERALDA AND ITS RECIPE NOTEBOOKS}

\begin{abstract}
The article, in the perspective of Cultural History, deals with the recipe books as documentary sources and as important pieces of the family and cultural heritage for its representativeness in memory and transmission of knowledge between generations. It deals with the life story of, N.L.M, the article the name Esmeralda, born and raised in the interior of Paraná, Brasil. It included bibliographical, field and documentary research. The recipe books are testimonies of a time, they deal with a way of life centered on family, in that it intends to systematize the food experience of this group. Her analysis reveals not only aspects related to the author's life as emotions, memories and family traditions, but also traces of what privileged the feminine education of the time.
\end{abstract}

Keywords: cultural history; life story; recipe notebook

\section{LA HISTORIA DE ESMERALDA Y SUS CUADERNOS DE RECETA}

Resumen

El artículo, en la perspectiva de la Historia Cultural, hace un estudio con los libros de recetas como fuentes documentales y como piezas importantes del acervo familiar y cultural por su representatividad en la memoria y la transmisión de saberes entre generaciones. Trata de la historia de vida de N.L.M, en este artículo llamada de Esmeralda, que nació y creció en una pequeña ciudad de estado de Paraná, Brasil. Es una pesquisa bibliográfica, documental y de campo. Los libros de recetas son testimonios de una época, tratan de una forma de vida centrada en la familia, en la medida en que pretende sistematizar la vivencia alimentar de este grupo. Su análisis revela no sólo aspectos relativos a la autora, como emociones, recuerdos y tradiciones familiares, pero también vestigios sobre la educación femenina de la época.

Palabras clave: historia cultural; historia de vida; cuaderno de recetas 
A história cultural ocupa-se com a pesquisa e a representação de determinada cultura, em dado período e lugar, com fulcro nas tradições da cultura popular, apresentando caminhos alternativos para a investigação histórica, valorizando o cotidiano e a micro-história. Para Chartier (1990, p. 15-16), a história cultural se propõe a "[...] identificar e explicar o modo como em diferentes lugares e momentos uma determinada realidade social é construída, pensada, dada a ler".

A história oral tem como objeto as representações sociais, as práticas culturais e os processos de apropriação, possibilitando a emersão de testemunhos em períodos específicos (SELAU, 2004). Alberti (2005, p. 29) afirma que a história oral "[...] por ser um método de pesquisa, [...] não é um fim em si mesma, e sim um meio de conhecimento". Assim, não se propõe mostrar verdades absolutas, mas, sim, apresentar a realidade do possível, a partir do depoimento do narrador, momento em que traz à tona suas experiências, suas aspirações, suas crenças, seus valores e seus ideais. A utilização da história oral como procedimento decorre do fato de poder ser empregada em pesquisas sobre temas recentes, ao alcance da memória dos entrevistados, possibilitando, a partir da reconstrução dos fatos históricos, a análise e a interpretação pelo historiador (VIEIRA, 2015).

Le Goff (1990, p. 32) aponta que o recurso à história oral e às histórias de vida pode auxiliar a base do trabalho científico e modificar a imagem do passado, dando a palavra aos esquecidos da história, sendo um dos grandes progressos da pesquisa histórica contemporânea. No entanto, Bloch (2002, p. 28) alerta que o essencial é enxergar que os documentos e os testemunhos "[...] só falam quando sabemos interrogá-los [...]; toda investigação histórica supõe, desde seus primeiros passos, que a investigação já tenha uma direção".

Nos últimos anos, de acordo com Abrahão (2013), a construção de novos estudos históricos a partir de fontes como os cadernos de receitas manuscritos possibilita aprofundar tanto as questões relacionadas à produção e ao consumo de alimentos, como os usos, costumes e ritos em um determinado espaço e tempo. Sendo assim, a análise dos cadernos de receitas revela não apenas aspectos relativos à sua autoria, mas também aspectos do contexto social e econômico no qual foram produzidos.

Nesse sentido, no presente estudo, com base na pesquisa documental e apoio na história oral, estabeleceu-se como objetivo conhecer a vida de N.L.M, neste artigo chamada de Esmeralda, nascida e criada no interior do estado do Paraná, Brasil, e seus cadernos de receitas. Por meio de entrevistas, buscou-se explorar a rotina familiar, como adquiriam e cozinhavam os alimentos, como era a transmissão das receitas culinárias e o papel dos cadernos de receitas nesse processo, investigando quais memórias estão a eles relacionadas.

Vieira (2015) considera que as histórias de vida têm como centro de interesse o próprio indivíduo na história, envolvendo sua trajetória desde a infância até o momento em que relata os diversos acontecimentos que presenciou ou vivenciou, de modo que o significado que as pessoas dão ao entorno e à sua vida são focos de atenção especial pelo pesquisador.

Esmeralda relata que nasceu em 14 de junho de 1959, no distrito de Apiaba, lugarejo da área rural do município de Imbituva, estado do Paraná. De uma família de descendentes italianos de classe média, de cor branca, cabelos loiros e olhos esverdeados, foi filha única até os oito anos, quando nasceu o primeiro irmão. Um segundo irmão viria anos depois.

Os pais eram alfabetizados, dominavam a escrita e a matemática do cotidiano e, como sempre moraram na área rural, não tiveram a oportunidade de continuar os estudos e frequentar um curso superior. Segundo Esmeralda, seus pais não consideravam primordial para o seu modus vivendi serem graduados. 
O pai cuidava das lavouras nas quais eram produzidos feijão, milho e batatas e outras culturas menores no tempo da entressafra. A mãe cuidava do armazém da família, o antigo bodegão,

[...] onde se podia adquirir de tudo, desde os mantimentos de primeira necessidade, até calças de brim coringa, camisas e botas de borracha, bem como bebidas, remédios populares e remédios homeopáticos como as Pílulas de Lussen e as Pílulas de Vida, entre outras. (ESMERALDA, 2018)

A família morava numa grande propriedade, um casarão de madeira com sótão e o armazém na frente, construído num imenso espaço, com três mangueiras ${ }^{1}$ distintas, cada uma com sua finalidade. No lado esquerdo da casa ficava o depósito onde era armazenado o feijão, já em sacas, enquanto se aguardava a vinda dos compradores das cidades ao redor. $\mathrm{Na}$ mangueira atrás da casa ficavam as baias dos cavalos e, ao lado direito, ficava o depósito do milho, local onde também eram tratados os porcos, as galinhas e os cabritos. Fazia parte da propriedade outro terreno grande, a invernada, onde ficavam as vacas destinadas à produção de leite.

Dessa forma, os relatos da entrevistada confirmam a percepção de Selau (2004), ao considerar a história oral como uma construção que o indivíduo faz de seu passado com base nas experiências guardadas por sua memória e aponta a contribuição das fontes orais para o estudo de grupos até então negligenciados nos documentos oficiais e por uma lógica de pesquisa que não os levava em consideração. Os historiadores que se interessavam pela história das chamadas minorias (imigrantes, trabalhadores, mulheres, crianças, idosos) passaram a utilizar as fontes orais como uma possibilidade de reconstituição da trajetória desses grupos.

Além das duas empregadas domésticas que auxiliavam a mãe, havia ainda os operários da lavoura, totalizando cerca de 20 pessoas. Como era necessário preparar refeições para a família e para todos os empregados, Esmeralda era solicitada a auxiliar nas tarefas da casa e da cozinha, enquanto os irmãos não tinham essa obrigação. Desse contato inicial com os afazeres domésticos, surgiu o interesse pelas receitas.

A narrativa de Esmeralda corrobora o entendimento de Demeterco (1998) quando afirma que em nossa civilização a história alimentar tem como base a relação simbólica e concreta estabelecida entre a mulher e a alimentação, considerando que o espaço da cozinha se constitui no espaço da mulher. Portanto, de acordo com a autora, ao se estudar a cultura e as histórias de vida dos indivíduos relacionadas à alimentação, não há como excluir a reflexão do papel da mulher como precursora do aprendizado alimentar desde a amamentação até a transmissão de saberes e práticas alimentares de geração a geração. Além disso, a história do cotidiano familiar doméstico apresentase como uma real possibilidade de realizar uma análise das relações sociais que espelham uma sociedade.

Uma das empregadas, que se chamava Andreza, alfabetizou Esmeralda, utilizando sua própria cartilha, e as aulas de Matemática eram ministradas pela mãe. Cedo, pela manhã, Esmeralda era levada pela Professora Zulmira até a escolinha multisseriada que ficava cerca 100 metros da residência da família, salvo nos dias em que ela não queria ir, já que para os pais a frequência escolar era irrelevante. A menina também nunca participava das avaliações feitas pelos inspetores que vinham da cidade para auferir o rendimento dos alunos.

Esmeralda relata que a mãe ensinava as prendas domésticas, que incluíam a costura, os bordados e a cozinha, como importantes para a educação das meninas. De acordo com Figueiredo (2011), aprender a cozinhar, tecer e costurar tinha um papel importante na formação da mulher, preparando a jovem para ser uma boa esposa, mãe e dona de casa. Esse exemplo referendava e

1 Área cercada destinada ao confinamento de animais ou depósito de cereais. 
preservava os modelos da feminilidade e excluía as mulheres dos espaços de protagonismo social ao valorizar apenas seu papel no interior dos lares e no desempenho da maternidade. O lar era o lugar no qual a mulher desempenharia seu melhor papel, no qual estavam depositadas sua esperança e felicidade. O casamento e a maternidade seriam os responsáveis por sua realização pessoal.

Conforme afirmações de Esmeralda, a mãe dava maior importância à educação doméstica que à educação formal. Sendo assim, além da alfabetização e do cálculo com as quatro operações da matemática, também cuidava para a filha estar sempre penteada e arrumada, o que lhe despertou a vaidade. Ainda, conta que sua mãe a ensinou desde cedo a manter a barriga contraída e a postura ereta, conselho que segue até hoje.

Em algumas regiões do país, a educação doméstica chegava a ser mais importante que a escolar ou a profissionalização, sendo inclusive as moças retiradas precocemente do ensino básico para aprender esses ofícios. Por essa razão, durante um longo período, as mulheres dedicaram-se ao espaço privado e, consequentemente, ficaram afastadas da educação formal (FIGUEIREDO, 2011).

A família mudou-se para Irati, para que Esmeralda começasse a estudar regularmente, visto ter sido alfabetizada em casa. Como sabia ler e escrever, além de realizar as quatro operações matemáticas, foi matriculada diretamente no segundo ano primário, em meio período. A partir do quinto ano, após fazer o exame de admissão, começou a estudar num colégio dirigido pelas irmãs da Ordem Vicentina.

No depoimento de Esmeralda, observa-se o que ela considerava importante para a educação das mulheres nesse período. Ao se referir ao Colégio das Irmãs Vicentinas, afirma:

Nesta Instituição aprendi muitas coisas de imenso valor para a vida prática. Como alguns exemplos, cito: desenho, prendas domésticas simples, mas imensamente importantes e úteis em nosso cotidiano, como pregar botões, fazer barras, bem como outras especialidades voltadas para trabalhos mais delicados e sofisticados, como pregar rendas em 'Ponto Paris', 'Ponto Ajour' para acabamentos em peças de enxoval para a casa. Também barrinhas artísticas e, principalmente, os bordados em diversos pontos como: o ponto cheio, ponto haste, ponto atrás, ponto picuru, ponto areia, ponto escama e ponto rococó, além de outros mais. (ESMERALDA, 2018).

$\mathrm{Na}$ sequência, sua narrativa destaca a importância dessas habilidades ensinadas na escola porque admirava a mãe, que,

[...] além de cuidar do armazém, cozinhar, cuidar da casa e das roupas da família, ainda fazia algumas peças de roupas para mim, especialmente tricô, bordado e crochê, que era o artesanato que ela mais gostava. Fez muitas peças de enxoval que ainda tenho comigo e uso. Gosto muito. São obras de arte, tamanha beleza e capricho. (ESMERALDA, 2018)

Afirma que os pais educaram e trataram os filhos da mesma forma, porém com uma diferença: como menina, não podia sair a qualquer hora ou ir ao local que quisesse, pois os pais selecionavam as pessoas com quem ela podia conviver. Também relata que não pôde continuar os estudos e fazer um curso superior, por não haver faculdades no município e o pai não permitir que ela fosse estudar fora. Outra diferença era que os irmãos estavam dispensados das tarefas domésticas.

Da infância, recorda-se que durante o verão brincava com sua amiga Cleuza, todos os dias, num belo riozinho de pedras que delimitava a divisa das terras de seu pai com outra propriedade. 
Esmeralda, sua mãe e irmãos gostavam muito de ler, enquanto seu pai apreciava jogar víspora com amigos. A respeito das leituras, menciona os gibis no princípio, depois as revistas de fotonovelas e outras revistas da época, além de alguns livros, embora não tenha recordado os autores lidos.

No período em que estava no colégio das Irmãs Vicentinas, ressalta que além de aprender muitas coisas e utilidades, começou a se interessar pelas receitas culinárias, já que toda a sua família cozinhava, especialmente massas, devido ao fato de serem de descendência italiana. Ela utilizava muito o Livro de Receitas da avó paterna, que era dividido em receitas de pratos salgados, triviais e de doces, que eram compostos principalmente de massas e bolos de todos os tipos. Destaca que a avó tinha um imenso ciúme desse livro "[...] porque era realmente um livro respeitável, de ótimas receitas e do qual copiei as que mais me interessavam no momento".

Assim, é possível concluir que os cadernos de receitas revelam interações sociais com base na oralidade e na escrita, pois, de acordo com Abrahão et al. (2007, p. 17), "[...] foi a partir da transcrição de diferentes sistemas e tradições culinárias que muitas sociedades desenvolveram uma escrita e uma literatura, e até mesmo um gosto pela leitura".

Por influência da mãe e da avó, Esmeralda começou a produzir seus próprios cadernos de receitas, atividade que perdurou até pouco depois de completar 13 anos. Ela registrava em seus cadernos as receitas selecionadas do livro da avó e os ilustrava com fotos retiradas de revistas. Relata que "[...] das revistas recortava fotos e figuras de pratos de receitas para colar em seu caderno e assim deixá-lo mais bonito e receber elogios de sua mãe e avó".

De acordo com Santos (2011), esta forma de passagem das receitas revela a ideia de pertencimento a um grupo de "iguais" para o repasse de um conhecimento que a princípio não estaria acessível à maioria. É o caso das tradições alimentares, receitas que são importantes para determinadas famílias por serem da preferência de alguém que mereça essa distinção ou por fazerem parte das refeições que costumam marcar eventos especiais.

Conforme destaca Freitas (1996, p. 2), “[...] a comida representa a manifestação da organização social, a chave simbólica dos costumes, o registro do modo de pensar a corporalidade no mundo, em qualquer que seja a sociedade". Além disso, transmitir o saber culinário também possui a função de manter práticas e ideologias alimentares passadas de geração a geração, representando importante maneira de manter as tradições familiares e culturais vivas na memória das pessoas (FIGUEIREDO, 2011).

De seu depoimento, percebe-se que Esmeralda procurava imitar a mãe e a avó, o que nos remete a Heller (2000, p. 36), que considera não haver vida cotidiana sem imitação. Sem a imitação, nem o trabalho nem o intercâmbio social seriam possíveis. A autora destaca que a vida cotidiana não está fora da história, mas no centro do acontecer histórico. O ser humano já nasce inserido em sua cotidianidade e participa na vida cotidiana com todos os aspectos de sua individualidade, de sua personalidade (HELLER, 2000, p. 17). A afirmação de Esmeralda reforça o entendimento de Heller (2000).

Os Cadernos de Receitas fazem parte da nossa cultura. Todas as famílias que conhecíamos tinham o hábito de fazer esses cadernos, assim como trocar receitas, mas não os emprestávamos. Uma questão de cuidados e até de ciúmes. Afinal, passamos muito tempo da nossa vida cuidando da alimentação. Quando crianças, fazíamos capinhas bem bonitas para os cadernos de receitas para presentear nossas mães. Eu própria ganhei alguns feitos por meus filhos, com o maior carinho. (ESMERALDA, 2018) 
Os cadernos de receitas culinárias, até os anos 1970, eram dirigidos especialmente às mulheres, consideradas as rainhas do lar. Durante esse período, era comum a passagem dos cadernos de mães para filhas.

As receitas culinárias adquirem assim uma importância simbólica, constituindo-se num meio por meio do qual se mantêm os vínculos a essas tradições e se reconstituem identidades sociais (DEMETERCO, 1998, p. 120).

\begin{abstract}
Algumas receitas evocam lembranças de outros tempos - geralmente da infância - ou de pessoas cuja personalidade ficou para sempre ligada a determinado prato ou ao modo de prepará-lo. São lembranças gustativas, olfativas e afetivas, ligadas ao universo da cozinha e às pessoas que se encarregavam dela. Existem certas receitas que não são preparadas por ninguém como sua 'dona' as prepara, fato que liga essa pessoa para sempre (ao menos enquanto se tenha a lembrança) à receita que criou.
\end{abstract}

Durante a primeira metade do século XX, vigorava a transmissão do modo de cozinhar "de mãe para filha", quando muitas vezes eram divulgados "segredos culinários", como aponta Demeterco (1998). Segundo a autora, esse modelo caracterizava-se como uma forma de transmissão oral de tradições, entendendo-se por tradição os modos de comportamentos e padrões produzidos por grupos sociais, selecionados pelo grupo como sendo importantes elementos identificadores e agregadores desse próprio grupo.

Santos (2011) destaca que, a partir da segunda metade do século XX, o espaço da cozinha foi incorporando aos poucos os alimentos industrializados e as inovações tecnológicas, como os novos fogões, geladeiras, freezers, panelas de pressão, fornos de micro-ondas e outros eletrodomésticos. Ainda, o ritmo ditado por uma nova sociedade do trabalho afetou a estrutura familiar, pois fez com que as mulheres pudessem entrar massivamente no mercado de trabalho e acalentar outros sonhos de consumo, o que implicou em mudanças nos hábitos alimentares.

Nesse contexto, os cadernos de receitas de comidas oferecem a possibilidade de descobrir um pouco da história e da cultura de uma sociedade ou segmento social e se constituem como importantes produtos da cultura dos lares de um grupo de mulheres, por revelar os vestígios de seu cotidiano nesse período.

\title{
CADERNOS DE RECEITAS: OS REGISTROS DE ESMERALDA
}

$\mathrm{Na}$ análise desses cadernos de Esmeralda, buscou-se verificar as condições de criação e preservação das receitas e como eram sistematizadas nesse material. Foram examinados os tipos de anotações, quais ingredientes eram mais utilizados, a quantidade de apontamentos para doces e salgados, informações referentes à pessoa que copiava essas receitas e o porquê de sua preservação.

A memória é uma categoria-chave nessa análise, uma vez que se vai trabalhar com história oral e ela se constitui em importante categoria para qualquer análise histórica, pois, enquanto visão subjetiva do passado, é sempre uma representação e deve ser interpretada como um produto cultural. Com apoio em Halbwachs (1990), entende-se que para poder investigar hábitos ligados à alimentação e, principalmente, à sistematização e à transmissão de receitas culinárias, é essencial analisar as transformações ocorridas no âmbito da domesticidade.

Lima (2015) considera que a alimentação oferece a possibilidade de descobrir um pouco da história e da cultura de uma sociedade ou de um segmento desta, mais especificamente dos grupos familiares. Segundo a autora, quando se alimentam, normalmente as pessoas não percebem que, além de suprir necessidades vitais, realizam um ato social complexo. Desse modo, os cadernos de 
receitas tornaram-se objetos de estudo capazes de serem abordados sob múltiplos olhares. A partir da leitura de como uma família prepara determinada comida, possibilita que sejam decifrados seus códigos implícitos, como emoções, lembranças e tradições familiares.

Para Santos (2011), os significados históricos, antropológicos e sociológicos da comida presentes nos cadernos de receitas permitem tratar de um universo sob múltiplos olhares, podendo trazer luzes sobre a produção de alimentos, a evolução dos preços, as políticas de importação e exportação de ingredientes, as mudanças no gosto, bem como as relações de classes e de gênero envolvidas na criação ou no consumo de determinados pratos.

Neste artigo, são avaliados dois cadernos de receitas de Esmeralda: o caderno 1, com 90 receitas, sendo 78 doces e 12 salgadas, produzido entre 1970 e 1971; e o caderno 2, com 82 receitas salgadas, produzido entre 1972 e início de 1973. São cadernos escolares pautados, comuns, com 96 folhas cada um, sem capas, com páginas amareladas, algumas salpicadas por um pouco de farinha e outras com manchas de óleo. Esmeralda aponta que algumas páginas dos cadernos estão manchadas porque eles sempre ficam sobre a mesa, com o fermento, a farinha e o açúcar. Explica que ao "[...] bater um bolo, é comum cair um pouco de farinha, pingar uma gota de óleo ou um tantinho de leite e isso é bom, mostra que ele está sendo usado, folheado e, principalmente, sendo útil”.

Para o registro das receitas, foi utilizada caneta esferográfica azul. Algumas receitas apresentam rasuras, normalmente alterações da quantidade de determinado item. Todas as receitas foram escritas com letra cursiva, com as letras maiúsculas bem desenhadas. A composição das receitas segue um padrão estético que se inicia com o nome do prato centralizado e com a inicial de cada palavra em letra maiúscula. Os ingredientes são apresentados na sequência, cada um deles numa linha distinta. Na continuação, é mostrado o modo de preparo, geralmente em parágrafo único.

Algumas receitas fogem do padrão e contêm apenas os ingredientes. Outras, principalmente em pratos salgados, contêm os ingredientes sem especificar as quantidades, o que torna difícil o preparo da receita por outra pessoa. Santos (2008) observa que as receitas doces mostram maior rigor com relação à quantidade dos ingredientes e seu modo detalhado de preparo. Como exemplo, citamos a receita de uma torta de galinha, cujo recheio é assim descrito: "[...] passe a galinha na máquina, acrescente os ovos, trigo e manteiga e leve ao fogo". A receita não informa as quantidades dos ingredientes, se a galinha é crua ou pré-cozida, as partes da galinha utilizadas e em qual máquina ela deve ser passada.

Santos (2008) ainda destaca que das receitas testadas e aprovadas, muitas vezes, tem-se o registro apenas dos ingredientes, sem a forma de preparo. Tal constatação leva à percepção de que quanto mais antiga a receita, menos detalhado é o modo de sua execução. Para Santos, o fato indica a "[...] preocupação do autor com a posse da receita, da manutenção da sua originalidade, o que acaba diminuindo a chance de que outros possam chegar ao resultado final desejado" (SANTOS, 2008 , p. 4). A receita da bomba de chocolate também pertence a essa categoria, como se observa na Figura 1. 
Figura 1: Receita de bomba de chocolate na qual os ingredientes não são especificados

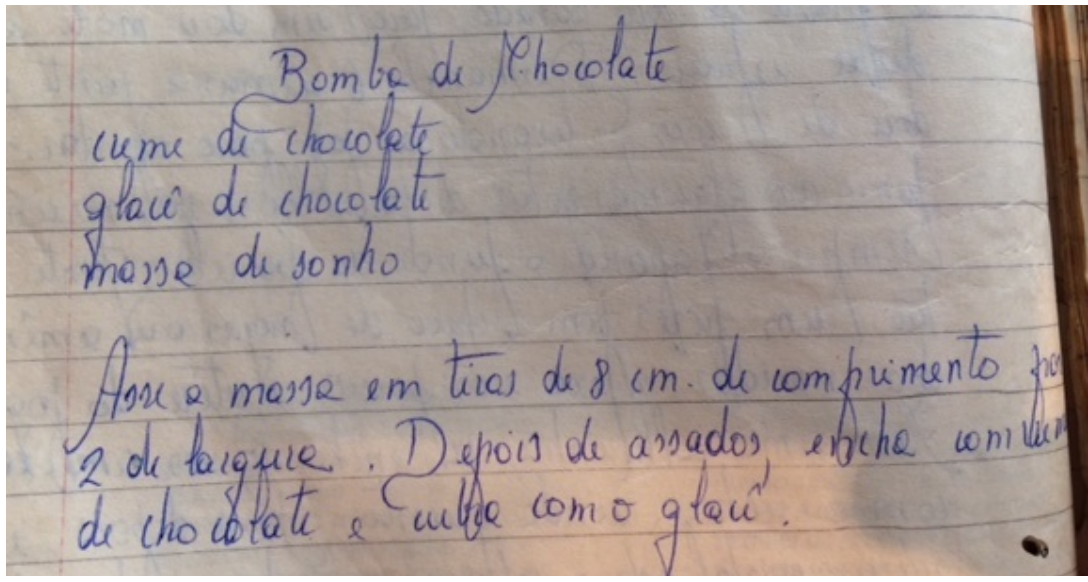

Fonte: Caderno de receitas da entrevistada, 1970.

As receitas doces incluem bolos, recheios e coberturas para bolos, tortas, doces, pudins, biscoitos, picolés e sorvetes. Já as salgadas incluem massas, sanduíches e canapés, empadas e pastéis, sopas, saladas, receitas com arroz e receitas com carne, aves e crustáceos.

Ao contrário dos pratos salgados, muitas das anotações de doces possuem nomes espirituosos ou poéticos, como: beijo de caboclo, baianinhos, cabeça de negro, lambe dedo, não me toques e biscoitos bichos da seda. Demeterco (2003) considera que isso ocorre porque o doce sempre teve uma conotação de bem-estar e está correlacionado às nossas lembranças gustativas.

Algumas receitas aparecem nos cadernos mais de uma vez. Entretanto, naquelas que estão repetidas, houve certo aprimoramento de informações na forma de execução, pela inclusão ou exclusão de alguns itens que as compunham, como na receita do bolo Nega Maluca (Figuras 2 e 3). Santos (2008) considera que isso ocorre porque enquanto variedade de literatura oral, as técnicas de preparo da comida são sujeitas aos mesmos fenômenos da literatura oral: esquecimento, improvisação, imprecisão, simplificação e mistura de elementos pertencentes a diversas receitas. É dessa complexidade que se constrói um saber culinário, o que muitas vezes acaba por consolidar certo padrão alimentar.

\section{Figura 2: Primeira receita de bolo Nega Maluca}

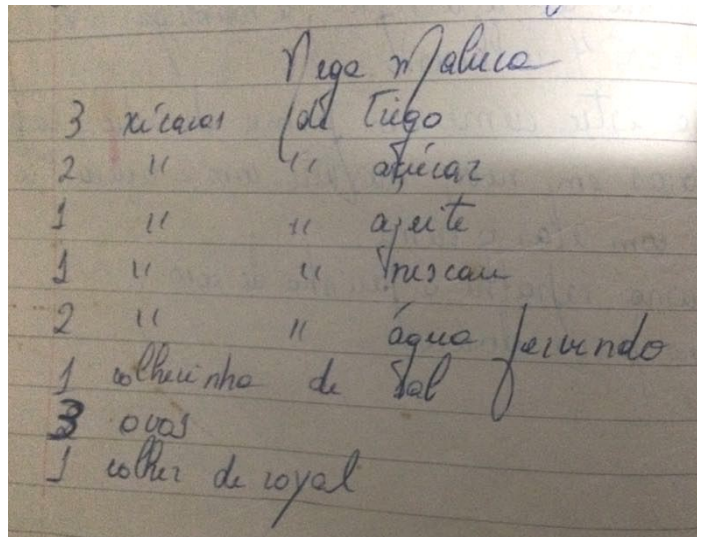

Fonte: Caderno de receitas da entrevistada, 1970.

Figura 3: Segunda receita de bolo Nega Maluca 


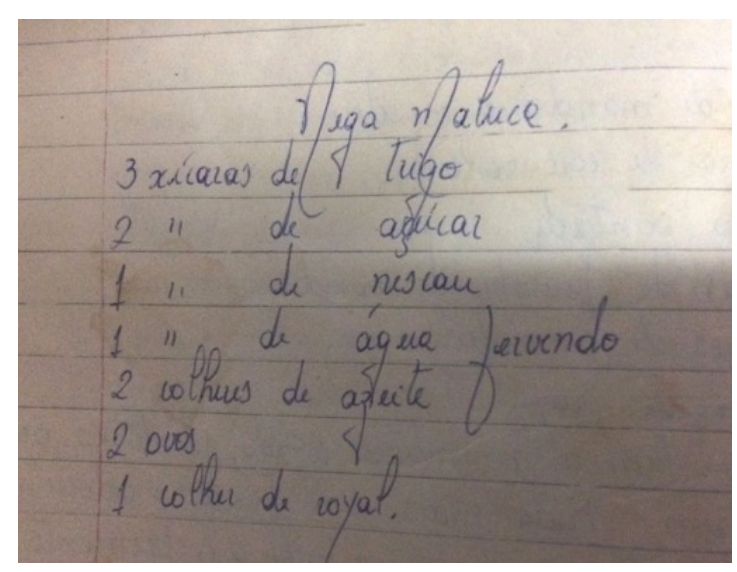

Fonte: Caderno de receitas da entrevistada, 1970.

Observa-se que em algumas receitas há divergências entre os ingredientes e o modo de preparo, tornando difícil sua execução. Como exemplo, a Figura 4 apresenta a receita do doce Paulistinha, em que se observa no modo de preparo a indicação de bater levemente os ovos, item que não aparece nos ingredientes. Provavelmente esta foi uma receita anotada, mas não executada.

\section{Figura 4: Receita do doce Paulistinha - divergência entre os ingredientes e o modo de preparo}

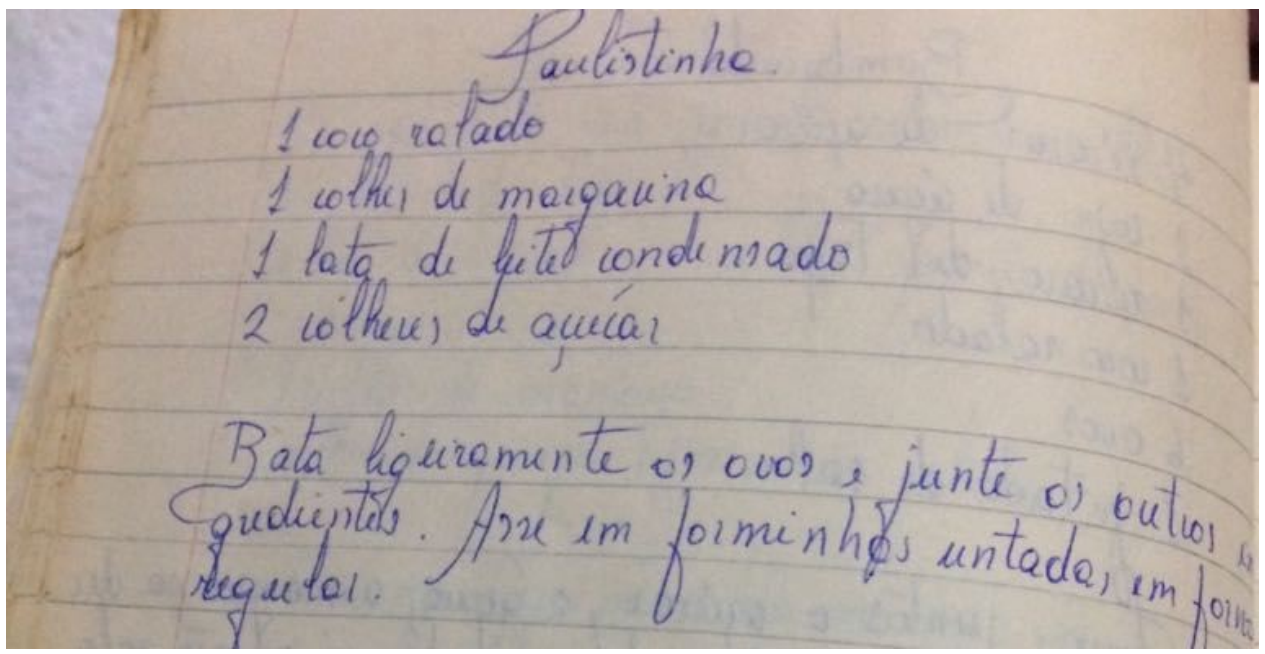

Fonte: Caderno de receitas da entrevistada, 1971.

Nesse tipo de caderno, de acordo com Beber e Gastal (2017), as memórias escritas da cozinha registram conhecimentos tradicionais, resguardando sua transmissão por gerações e codificando práticas e técnicas, mesmo que na maioria dos casos tais registros, em sua origem, aspirassem apenas à orientação pessoal da responsável pela sua escrita.

Para Lacerda (2000), alguns cadernos trazem também dicas e conselhos de cozinha e de como gerenciar corretamente uma casa. Segundo Demeterco (1998), além das receitas culinárias, é comum encontrar, nesses materiais, comentários ligados a indicações e conselhos de cozinha, poesias, orações e outras anotações diferentes. No caso do material de Esmeralda, comprovamos o afirmado pelos autores, já que encontramos receitas de tricô e listas de enxovais para bebê nos dois cadernos analisados, como mostram as Figuras 5 e 6 , o que indica que ela continuou a utilizálos mesmo na vida adulta, como afirmado pela entrevistada. 
Figura 5: Receita de tricô, constante no caderno de receitas

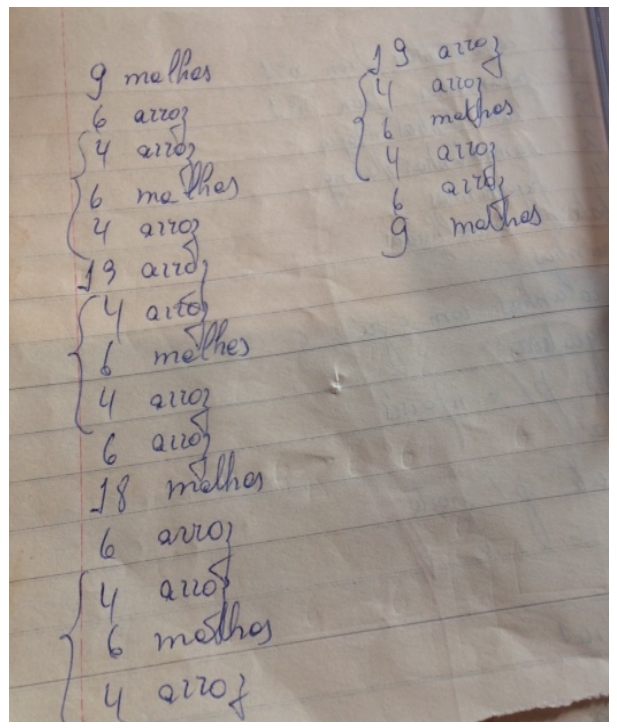

Fonte: Caderno de receitas da entrevistada, 1980.

Figura 6: Enxoval de bebê constante no caderno de receitas

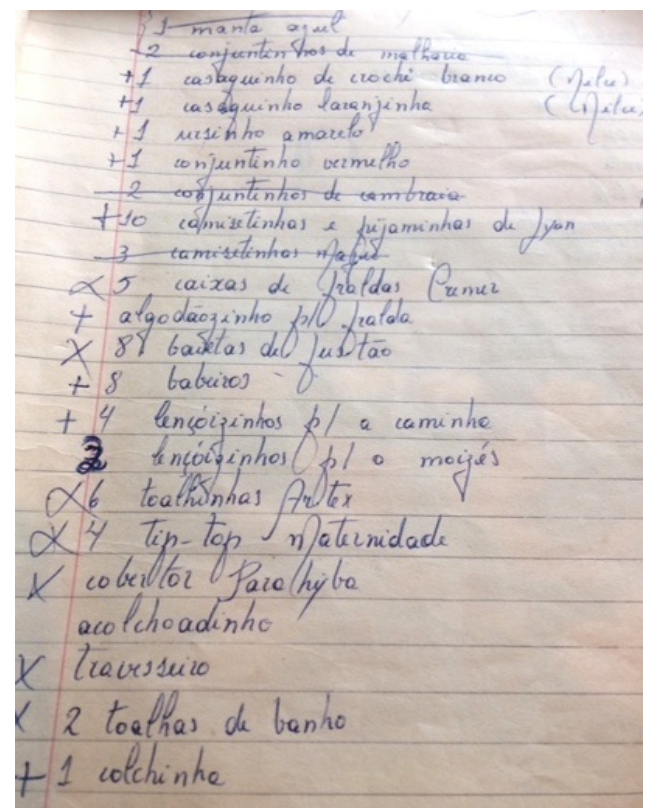

Fonte: Caderno de receitas da entrevistada, 1980.

Além disso, conforme destaca Demeterco (1998), para algumas mulheres, o tempo dispensado à organização de seu caderno era um tempo só seu, de lazer mesmo, fato confirmado pela entrevistada quando relata que adorava ficar bastante de tempo copiando as receitas dos cadernos da mãe e da avó e, mesmo tão pequena, imaginava como seria sua cozinha.

Nas entrevistas realizadas, ela mostrou-se bastante apegada aos seus cadernos, enumerando as lembranças que cada uma das receitas trazia e mencionando que as utiliza até hoje, principalmente aquelas que seus dois filhos, embora já adultos, continuam a lhe pedir. De acordo 
com Almeida (1998), a linguagem oral, usada pelo narrador e captada pelo entrevistador na prática de ouvir histórias representadas por lembranças recuperadas pela memória, tem sido uma das escolhas metodológicas da História Oral e vem privilegiando um lado subjetivo e afetivo do ser humano, que é o desejo de contar histórias, de dar depoimentos sobre sua vida e de relembrar o passado, como se assim esse tempo pudesse, de alguma forma, novamente estar presente.

Esmeralda finaliza seu depoimento com a seguinte declaração:

Naqueles tempos, raríssimas mulheres trabalhavam além das atividades domésticas e educação dos filhos, salvo aquelas que possuíam empresas familiares, assim como minha mãe, que por vários anos se dedicou a administrar nosso armazém. A rotina feminina era voltada basicamente aos cuidados da casa e criação e educação dos filhos, além de encontros sociais com as parentes e amigas regados a chás e quitutes que as próprias mulheres faziam. Todavia, as mulheres daquela época geralmente procuravam aprender várias modalidades de artesanato, como tricô, crochê, bordados em geral; algumas se voltavam para a costura e chegavam a se tornar profissionais. Aquelas que estavam numa posição social mais elevada até optavam por outros tipos de hobby, assim como a música ou a pintura, e isso até para passar o tempo e se distrair. Uma pequena observação: nenhuma dessas mulheres com quem convivi sofreu ou sofria de depressão, nem de hipertensão. Eram bem felizes. (ESMERALDA, 2018)

Almeida (1998) afirma que, nas primeiras décadas do século XX, o fim último da educação era preparar a mulher para atuar no espaço doméstico e incumbir-se do cuidado com o marido e os filhos. Esse panorama mudou com a entrada da mulher no mercado de trabalho e as primeiras exigências de igualdade de direitos, de educação e de profissionalização. No entanto, como destaca a autora, no ambiente mais conservador e provinciano das cidades do interior, ser mulher nessa época era quase como permanecer nos mesmos padrões estabelecidos no início daquele século. Esmeralda, embora tenha nascido na segunda metade deste século, deixa claro em seu depoimento que possui uma visão conservadora do papel da mulher e, implicitamente, denota-se a nostalgia dos costumes do passado, o que fica bem caracterizado com a observação com a qual ela encerrou a entrevista, além de fazer questão de frisar que se casou com um rapaz de família abastada e das mais tradicionais da cidade.

\section{CONSIDERAÇÕES FINAIS}

A história cultural promoveu a ampliação e a diversidade das fontes de investigação por meio dos cadernos escolares, diários, cadernos de receitas, representando, assim, vasto campo para pesquisa em História, concluindo-se que esses materiais podem se constituir como um produto de transmissão da cultura de um determinado período e lugar, à medida que propicia ao pesquisador olhar além do documento em si, pois nele está refletido o modus vivendi de seus autores.

Assim, a análise do arquivo pessoal da $\mathrm{Sr}^{\mathrm{a}}$. N.L.M., nesse artigo chamada de Esmeralda, buscou compreender e interpretar, em um contexto histórico, as marcas, as características e os aspectos da educação de uma mulher que nasceu e cresceu num município do interior do estado do Paraná, o que a torna singular em determinados aspectos. Nessa perspectiva, o presente estudo fez uma análise de questões inerentes ao dia a dia da entrevistada, por meio de registros dos cadernos de receitas, evidenciando a possibilidade de utilização desses materiais como fontes históricas.

A partir da análise de dois cadernos de receitas, e da entrevista, iniciados por Esmeralda desde os 11 anos de idade, quando residia no interior do estado do Paraná, foi possível descobrir 
marcas de sua singularidade e sobre o modo como expressou seus sentimentos, suas emoções, seus conhecimentos, suas certezas e seus valores. Foram observadas suas relações com a família, a atenção dada aos conteúdos escolares e às atividades voltadas às prendas domésticas quando passou a frequentar a escola, bem como a figura de cada membro da família naquela estrutura familiar patriarcal. No desenvolvimento da pesquisa, surgiram indícios que puderam ser relacionados diretamente à realidade na qual ela estava inserida: informações sobre seu cotidiano, seu comportamento como filha e mulher, sua interação com a colega de infância, Cleuza, a prática da escrita, por meio de cadernos de receitas, a importância do matrimônio, a conservação dos costumes até então impostos às mulheres, sem qualquer questionamento por parte delas.

Sob essa ótica, Esmeralda, como muitas mulheres da primeira metade do século XX, foi educada pela mãe e pela avó para o casamento e a maternidade - valores impostos que permanecem inalterados -, conforme se depreende de trechos da sua entrevista.

Além disso, pode-se afirmar que o conjunto de saberes e práticas envolvidos na cozinha de um grupo social faz parte de sua herança cultural. Como parte integrante da vida cotidiana, ocupa lugar relevante entre os marcadores da experiência do pertencimento, da identidade e do reconhecimento do próprio sujeito.

Para tanto, utilizar o caderno de receitas culinárias como objeto desta análise foi relevante não somente para buscar os elementos presentes em seu interior - não constituído apenas por receitas, mas por recortes de ordens variadas - mas resgatar uma forma de viver centrada na vida familiar, como mães, donas de casa, caso de muitas mulheres das cidades do interior do Paraná.

\section{REFERENNCIAS}

ABRAHÃO, Eliane Morelli. Cadernos de receitas manuscritos: a perpetuação dos saberes culinários. In: Simpósio Nacional de História: Conhecimento Histórico e Diálogo Social, 21., 2013, Natal. Anais... Natal: [s.n.], 2013, p. 1-17. Disponível em http://www.snh2013.anpuh.org/resources/anais/27/1364943774_ARQUIVO_ElianeMorelliAb rahao Anpuh2013.pdf. Acesso em 2 ago. 2018.

ABRAHÃO, Fernando Antônio et al. (org.). Delícias das sinbás: história e receitas culinárias da segunda metade do século XIX e início do século XX. Campinas: CMU-UNICAMP, Arte Escrita, 2007.

ALBERTI, Verena. Manual de história oral. 3. ed. Rio de Janeiro: Ed. FGV, 2005.

ALMEIDA, Jane Soares. Mulher e educação: a paixão pelo possível. São Paulo: UNESP, 1998.

BEBER, Ana Maria Costa; GASTAL, Susana. Cadernos de receitas e histórias de vida: consolidando memórias e saberes tradicionais. Revista Ideias, Manaus, v. 22, n. 1, p. 6-14, jan./jun. 2017.

BLOCH, Marc. Apologia da História on o ofício de historiador. Rio de Janeiro: Zahar, 2002.

CHARTIER, Roger. A bistória cultural: entre práticas e representações. Lisboa: Difel, 1990.

DEMETERCO, Solange Menezes da Silva. Sabor e saber: livros de cozinha, arte culinária e hábitos alimentares: Curitiba 1902-1950. 272 f. Tese (Doutorado em História), Faculdade de História, Universidade Federal do Paraná, Curitiba, 2003.

DEMETERCO, Solange Menezes da Silva. Doces lembranças: cadernos de receitas e comensalidade, Curitiba: 1900-50. 190 f. Dissertação (Mestrado em História), Setor de Ciências Humanas, Letras e Artes, Universidade Federal do Paraná, Curitiba, 1998. 
FIGUEIREDO, Samira Coutinho. Comida como narrativa: histórias de vida sobre experiências alimentares ao longo da vida. 118 f. Dissertação (Mestrado em Nutrição), Universidade Federal da Bahia, Bahia, 2011.

FREITAS, Maria do Carmo Soares de. Educação nutricional: aspectos socioculturais. In: Congresso Brasileiro de Nutrição, 14., 1996, Belo Horizonte. Anais... Belo Horizonte, 1996, p. 1-4.

HALBWACHS, Maurice. A memória coletiva. São Paulo: Vértice, 1990.

HELLER, Agnes. O cotidiano e a história. São Paulo: Paz e Terra, 2000.

LACERDA, Maria Thereza Brito. A lida da goiabada: contos e crônicas. Curitiba: Ed. do autor, 2000. LE GOFF, Jacques. História e memória. Campinas: Ed. UNICAMP, 1990.

LIMA, Joseni França Oliveira. Receitas culinárias de família como expressão de cultura. Revista Estação Cientifica, Juiz de Fora, v. 1, p. 1-15, jul. 2015.

SANTOS, Carlos Roberto Antunes. A comida como lugar da história: as dimensões do gosto. História: Questões \& Debates, Curitiba, n. 54, p. 103-124, jan./jun. 2011.

SANTOS, Carlos Roberto Antunes. Os pecados e os prazeres da gula. Os cadernos de receitas como fontes históricas. Palestra, UFPR, 2008.

SELAU, Mauricio da Silva. História Oral: uma metodologia para o trabalho com fontes orais. Revista Esboços, Florianópolis, n. 11, p. 217-228, jan./jun. 2004.

VIEIRA, Alboni Marisa Dudeque Pianovski. A História Cultural e as fontes de pesquisa. Revista HISTEDBR Online, Campinas, v. 15, n. 61, p. 367-378, mar. 2015.

ENTREVISTAS realizadas com a Sr. ${ }^{a}$ N. L. M. (neste artigo, Esmeralda), de 14 a 16 de junho de 2018.

ESMERALDA (2018). Entrevista realizada pelas autoras com N. L. M. (depoimento, 2018). Curitiba.

\section{Informações das autoras}

Elza Fagundes da Silva

Pontifícia Universidade Católica do Paraná

E-mail: efagundesilva@gmail.com

ORCID: https://orcid.org/0000-0003-0822-3172

Link Lattes: http://lattes.cnpq.br/8323595330649875

Alboni Marisa Dudeque Pianovski Vieira. 
Pontifícia Universidade Católica do Paraná

E-mail:alboni@alboni.com

ORCID: https://orcid.org/0000-0003-3759-0377

Link Lattes: http://lattes.cnpq.br/0198429449537597 